\title{
A questionnaire based evaluation of teaching methods in Pharmacology among second MBBS students in Shadan Institute of Medical Sciences Hyderabad, Telangana, India
}

\author{
Naseem Begum*, Ramesh Sathrasala, Bhawani Goru, Manikanta M., Sharanya M.
}

Department of Pharmacology, Shadan Institute of Medical sciences , Hyderabad, Telangana, India

Received: 20 March 2019

Revised: 02 April 2019

Accepted: 03 May 2019

*Correspondence to:

Dr. Naseem Begum,

Email: naseembegum007@

yahoo.com

Copyright: () the author(s), publisher and licensee Medip Academy. This is an openaccess article distributed under the terms of the Creative Commons Attribution NonCommercial License, which permits unrestricted noncommercial use, distribution, and reproduction in any medium, provided the original work is properly cited.

\begin{abstract}
Background: Pharmacology is one of the important subjects studied during second year MBBS. The general stigma among students regarding pharmacology is that it is a dry and boring subject. Hence lecturers need to reform their teaching methods in order to make pharmacology teaching interesting and a significant learning experience by the students.

Methods: A questionnaire based evaluation of 146 second MBBS students about teaching methods in pharmacology was conducted at Shadan institute of medical sciences, Hyderabad. Questionnaire was prepared from previous studies and validated by experts. The questionnaire was given to the students to be solved in one hour.

Results: The mean age of the students was 20 plus or minus 2 years. There were $73 \%$ females and $27 \%$ males. $85 \%$ of students felt that pharmacology is an interesting subject. $67.2 \%$ wanted more of group discussions. $50.4 \%$ did not want any student seminars. $53.9 \%$ felt there should be more of problem stimulated lectures in pharmacology. $92 \%$ were interested in computer assisted learning. $57.5 \%$ of students preferred learning from textbook and class lectures. $68.1 \%$ students preferred to study pharmacology for regular tests only, 92\% students wanted Multiple Choice Questions (MCQ's) to be discussed in class.

Conclusions: There is a definite need for modification of undergraduate curriculum so as to make pharmacology learning more understandable by students. Novel methods of teaching like small group discussions, computer assisted learning, bed side teaching etc can be adopted to make pharmacology an interesting and useful subject among students.
\end{abstract}

Keywords: Evaluation, Pharmacology, Questionnaire, Teaching methods

\section{INTRODUCTION}

The subject of pharmacology is the base for rational therapeutics. Pharmacology is introduced in the second year of MBBS curriculum. During second year medical students are versed with the pathophysiological concepts of diseases and their treatment. ${ }^{1}$ Besides studying these pre-clinical subjects, they also go to the clinics to see the patients. Thus, they begin to understand the concept of diseases and their treatment. Teaching pharmacology at this stage is a challenging job. ${ }^{2}$ The main objective of teaching pharmacology to undergraduate medical students is to enable them to make rational drug prescribing in their future clinical practice. ${ }^{3}$

During second year, pharmacology teaching is mainly through teacher assisted learning [TAL] in the form of didactic lectures and medical students are not trained adequately for therapeutic pursuits. ${ }^{4}$ Undergraduate pharmacology curriculum has not shifted much towards clinical pharmacology. Hence students find it difficult in remembering the names and concepts of different drugs. Pharmacology practical's focus on pharmacy and experimental pharmacology, the significance of these 
practical classes for their future clinical subjects has been questioned by most of the students. ${ }^{5}$ With a view to improvise the current teaching methodologies, this study was undertaken to get the feedback of teaching methodology and evaluation pattern in pharmacology subject from second MBBS students in Shadan Institute Of Medical Sciences(SIMS), Hyderabad.

\section{METHODS}

This was a cross-sectional questionnaire based study involving 113 medical students of second MBBS from Shadan institute of medical sciences, Hyderabad. The questionnaire contained 27 questions prepared from previous studies and validated by experts. The questionnaire included questions on teaching-learning methodology, evaluation methods, environment related to studying; the audio-visual aids used in teaching, examination pattern and some general questions. Second MBBS students of Shadan Institute of medical sciences, Hyderabad of age $>18$ years, both male and female students and willing to fill the complete questionnaire were included in the study. Those students who were not willing to fill the questionnaire and those who were absent on the day of the study were excluded from the study.

Total 146 questionnaires were prepared out of which 113 students were present on the day of the study. Hence 33 students who were absent on the day of the study did not participate in the study. The identity of the students and the data collected from them was kept confidential. The enrolled students were explained about the details of the study and its objectives. Questionnaire was given to the second MBBS students in the pharmacology department and they were asked to fill up the questionnaire in one hour time and give valuable suggestions if any. The filled questionnaire were collected from the students after one hour and analysed.

\section{Statistical analysis}

The data was analysed by using descriptive statistics. The results of the study were expressed in percentage.

\section{RESULTS}

Out of the total 146 students, 33 students were absent on the day of study. Hence 113 students participated in the study. Out of 113 students, $73 \%$ were females and $27 \%$ were males, the average age of the participants was 20 plus or minus 2 years. The students enjoyed answering the questionnaire and gave some valuable suggestions. $85 \%$ of students felt that pharmacology is an interesting subject, $12.3 \%$ of students did not find it interesting and $0.8 \%$ were neutral regarding this matter. Most of the students felt that pharmacology is a useful and interesting subject. $84.9 \%$ of students did not have any knowledge of pharmacology before entering second year MBBS and only $14.1 \%$ of students had knowledge of pharmacology before entering second year MBBS. When asked about the teaching method, $48.6 \%$ of students preferred didactic lectures whereas $67.2 \%$ students recommended group discussions, seminars, symposium and tutorials. $36.2 \%$ of students did not like didactic lectures and $32.7 \%$ students were not in favour of group discussions (Figure 1). $84 \%$ of students liked integrated method of teaching pharmacology with other subjects. Only $11.5 \%$ students did not like integrated teaching method.

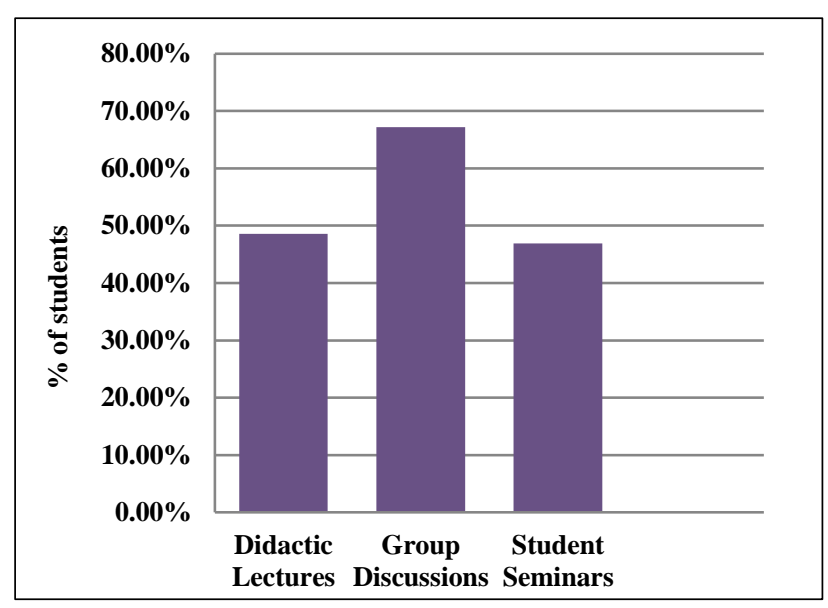

Figure 1: Different teaching methods.

The ideal teaching method preferred by second MBBS students was lecture plus power point presentation by $53.9 \%$ students whereas $43.3 \%$ students' preferred lecture plus chalk and board method (Figure 2). 57.5\% of the students wanted textbook and lectures as the source of learning pharmacology $29.2 \%$ students' preferred textbook and self-prepared notes whereas $13.3 \%$ students wanted to learn pharmacology from textbooks, lectures and selfprepared notes. $65.4 \%$ students preferred to read pharmacology from K.D Tripathy, $20.3 \%$ preferred Tara Shanbagh. Students felt that K.D Tripathy is an ideal textbook for reading on regular basis whereas Tara Shanbagh is good from examination point of view. $92 \%$ students wanted competitive entrance examination level MCQS to be discussed in class. $68.1 \%$ of students read pharmacology for regular tests and only $31.8 \%$ students read pharmacology on regular basis so there is a need for conducting exams frequently. $61 \%$ did not wanted the pharmacology lectures to be increased. When asked about the duration of pharmacology teaching $55.7 \%$ students wanted the duration to be one year six months, $25.6 \%$ students wanted it to be one year whereas $15 \%$ of the students wanted the duration to be two years. The duration of pharmacology lecture preferred by $66.3 \%$ students was 45 minutes, $10.6 \%$ wanted it to be for one hour and $23 \%$ wanted to cut it short by 30 minutes. Students were asked about the lecture halls to be provided with internet facility and air-conditions, $94.6 \%$ were in its favour.

Most of the students were interested in novel methods of teaching $53.9 \%$ of the students were interested in problem stimulated lectures, $38.9 \%$ students were not in this favour $87.6 \%$ of the students were interested in introduction of 
recent advances in pharmacology curriculum (Figure 3). When asked about demonstration of animal experiments by computer assisted learning $70.7 \%$ of students were excited about this whereas $25.6 \%$ were against this as they might not be knowing about computer assisted learning as this is a very recent concept, $92 \%$ of students were interested in active learning such as computer assisted learning, use of models and working on mannequins for concept understanding. $94.6 \%$ of students wanted pharmacology to be integrated with medicine. When asked about their interest in bedside training of clinical pharmacology during second MBBS, $89.3 \%$ students showed interest and $8.8 \%$ did not like it. When asked about increasing the numbers of student seminar $50.4 \%$ students were not in its favour and only $46.9 \%$ wanted student seminars to be increased.

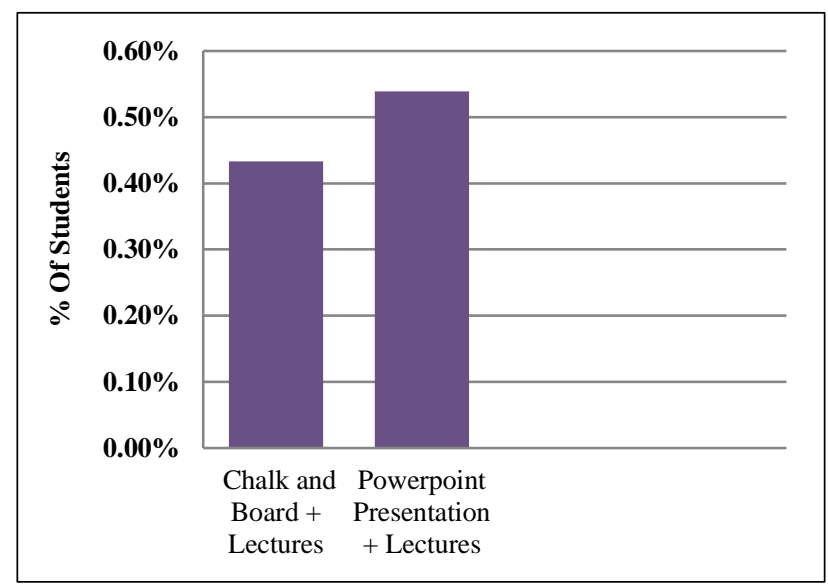

Figure 2: Medium of teaching.

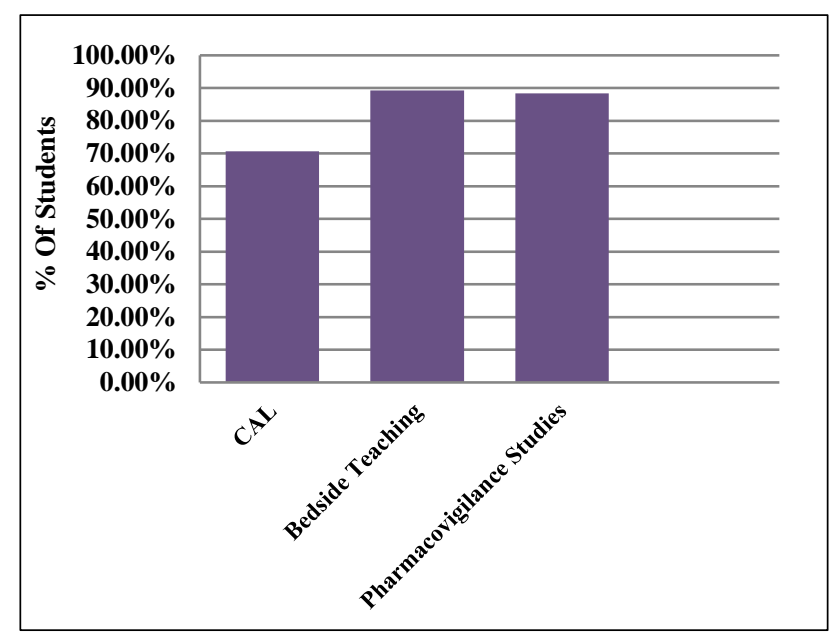

Figure 3: Novel methods of teaching.

Further, students were questioned about innovative teaching and learning methods and students were very much interested. $88.4 \%$ students wanted pharmacovigilance cases to be discussed in practical pharmacology to understand adverse drug reactions better. $87.6 \%$ students wanted recent advances to be introduced in pharmacology curriculum $8.8 \%$ students were against this. When asked about the examination pattern $74.3 \%$ students preferred MCQS, 21.2\% wanted long and short questions whereas $4.4 \%$ preferred both MCQS and long and short questions (Figure 4). The KNR university gives a gap between pharmacology paper one and paper two during final exams when asked about this gap, $95.5 \%$ student were in favour of the gap between two papers. Finally, $98.2 \%$ of the students felt that better knowledge in pharmacology subject will help them to become better clinicians in their future clinical practice.

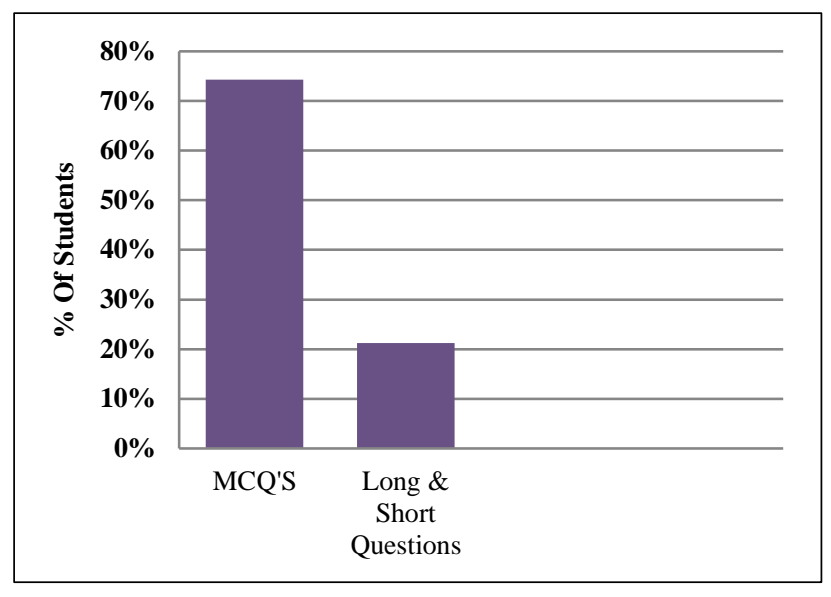

Figure 4: Examination pattern.

\section{DISCUSSION}

Feedback from second year MBBS students reveals that majority of the students are females, this shows that medical profession is becoming very popular among women. $84.9 \%$ of students did not have any knowledge of pharmacology before entering second year MBBS. So, at the start of first year of MBBS, an overview of different subjects should be briefed to the students. $85 \%$ of students felt that pharmacology is an interesting subject but they thought that it is a difficult and volatile subject. The mindset of the students can be changed by teaching pharmacology in a simple way with understandable illustrations. Most of the students preferred group discussions over didactic lectures. ${ }^{6}$ Didactic lectures can be monotonous and boring. Seminars, symposium, tutorials, etc help the students understand the subject with ease and interest. Bilateral communication enables student's participation in discussions and this improves the performance of students in exams. ${ }^{7}$

Apart from theoretical teaching, majority of student's favour incorporation of problem based learning, clinical case study, recent advances in pharmacology, computer assisted learning, vertical and horizontal integrated teaching programmes and demonstration on models and mannequins in regular pharmacology curriculum. So, in this way students understand the concept in a better and interesting way. Majority of the students favour clinically innovating teaching programs like bedside training of clinical pharmacology during second MBBS. ${ }^{8}$ Students should be taken to the wards during the practical classes so that the treatment protocols of the admitted cases can be 
discussed. A clinically oriented program by name CAREbased program-which stands for Concepts, Application, Rationale and Essential drugs has been started in Surat, India. ${ }^{9}$ Such teaching methods can be introduced in order to make students understand the concept of rational use of drugs. Bedside learning of pharmacology will allow the students to retain the knowledge of pharmacology when they reach the final year.

Computer assisted learning [CAL] can be a potential teaching methodology in the future. ${ }^{10} \mathrm{CAL}$ has its own advantages of reduction in animal use, the drug effects can be clearly demonstrated, even difficult experiments can be easily illustrated. Moreover, expenses involved in animal experiments can be reduced by CAL. $46.9 \%$ students were in favour of student seminars and $50.4 \%$ of students did not want more number of seminars. ${ }^{11}$ This goes well with the previous studies. To make seminars popular among students, there is a need to develop certain strategies to make them interesting. Clinical seminars can also be introduced to make pharmacology easily understandable by the students. MCI has put emphasis on integration of pharmacology with medicine. ${ }^{12}$ Various studies are also of the same opinion that the students will not only get knowledge of various diseases but they will also get a chance of learning about different drugs.

$53.9 \%$ preferred lecture plus power point presentation as an ideal teaching method. Power point presentation helps in illustration of elaborative diagrams, screening small videos on different drugs. $43.3 \%$ of the students preferred lecture plus black board as the ideal teaching method. The reason for liking chalk and board is that the lectures contain small breaks allowing the students to make notes. ${ }^{13}$ There is no issue of power cuts. $50.4 \%$ did not like chalk and board, as some times the handwriting is not legible. Moreover, illustrious diagrams could not be represented properly. Some students disliked power point presentation, the reason behind this could be poor visibility and more matter is covered quickly in short time. $2.6 \%$ students preferred chalk and board as well as power point presentation, provided the lecturer is clear and audible and students should be given sufficient time to note down the important points, diagrams and flow charts.

Exams serve as the driving force for the students to learn. This study has showed that most of the students preferred learning during regular tests; hence they found the internal assessment exams to be useful. MCQ test and pharmacology Quiz can be conducted at the end of every topic and during revision classes so that the students understand the subject properly. ${ }^{14}$ In this study, most of the students $(92 \%)$ preferred the class duration to be of 45 minutes. Hence, last 10 minutes can be spent in discussing MCQS on that particular topic.

\section{CONCLUSION}

This study reveals that there is a definite need for modification of undergraduate curriculum so as to make pharmacology learning more interesting and understandable by students. Students demand more of group discussions, MCQ based revisions at the end of each theory class, integrated teaching programs, clinical oriented problem based learning and novel methods of teaching like computer assisted learning in practical pharmacology, role plays and pharmacovigilance studies.

\section{ACKNOWLEDGEMENTS}

Authors would like to thank Dr. Sarib Rasool Khan, Managing Director, Shadan Institute of Medical Sciences, Dr. S Jagannatham and Dean, SIMS for their support.

Funding: No funding sources

Conflict of interest: None declared

Ethical approval: The study was approved by the Institutional Ethics Committee

\section{REFERENCES}

1. Tabish A, Sharma A, Syed AS, Sharma R, Mahendra J. Assessment of effectiveness of different teaching methodologies in pharmacology for undergraduates at a rural medical college of Bastar region. Int J Biomed Res. 2015;6(07):512-7.

2. Sudha J. Chapter-21 Graduate training programmes in pharmacology in India. Health Administrator. 2006;19(1):88-91.

3. Bapna JS. Experiences in teaching rationale drug use. Indian J Pharmacol. 1993 Jan 1;25(1):2-4.

4. Bhavsar VH. Experience regarding modification of teaching and the evaluation pattern in practical pharmacology. Indian J Pharmacol. 2004;36(6):385-9.

5. Gurumadhva RS, Sudhakara K, Vasanth K, Udupa AL, Bairy KL, Ahalya D. A scheme of practical examination in pharmacology for evaluating skills involved in problem solving. Indian J Pharmacol. 1992 Jul 1;24(3):145.

6. Papanna KM, Kulkarni V, Tanvi D, Lakshmi V, Kriti L, Unnikrishnan B, et al. Perceptions and preferences of medical students regarding teaching methods in a Medical College, Mangalore India. Afr Health Sci. 2013;13(3):808-13.

7. Kaufman M, Mann V Achievement of students in a Conventional and Problem-Based Learning [PBL] Curriculum. Adv Health Sci Edu. 1999;4(3):245-16

8. Sim SM. Teaching of pharmacology in university Malaya and the other medical schools in Malaysia: a historical perspective. Acta Pharmacological Sin. 2004;25(9):1209-19.

9. Kela AK, Mehta VL. Impact of inclusion of clinical projects in undergraduate teaching. Indian $\mathbf{J}$ Pharmacol. 1993;25(4):249-50.

10. Kuruvilla A, Ramalingam S, Bose AC, Shastri GV, Bhuvaneswari K, and Amudha G. Use of computer assisted learning as an adjuvant to practical pharmacology teaching: Advantages and limitations. Indian J Pharmacol. 2001;33(4):272-5. 
11. Garg A, Rataboli PV, Muchandi K. Students' opinion on the prevailing teaching methods in pharmacology and changes recommended. Indian J Pharmacol. 2004 May 1;36(3):155.

12. Vision 2015. New Delhi:Medical Council of India;2011. Available at: www.mciindia.org/tools/announcement/MCI_booklet .pdf. Accessed on 14 dec 2011

13. Rani V, Tekulapally K, Shyamala R, Simpson GB. Assessment of effectiveness of different teaching methodologies and perception about pharmacology among 2nd year dental students: A cross-sectional study. Int J Health Allied Sci. 2017 Apr 1;6(2):64.

14. Desa SB, Keny MS. Power point versus chalk board based lectures in Pharmacology: Evaluation of their impact on medical student's knowledge and their preferences. Int J Adv Health Sci. 2014;1(5):10-4.

15. Agarwal R, Ismail NF. Student's perception of teaching methods in Pharmacology in a Malaysian medical school. J Clin Health Sci. 2016;(1):16-21.

Cite this article as: Begum N, Sathrasala R, Goru B, Manikanta M, Sharanya M. A questionnaire based evaluation of teaching methods in Pharmacology among second MBBS students in Shadan Institute of Medical Sciences Hyderabad, Telangana, India. Int J Basic Clin Pharmacol 2019;8:1283-7. 